\title{
Sweeping Dishonesty under the Rug: How Unethical Actions Lead to Forgetting of Moral Rules
}

\section{Citation}

Shu, Lisa L., and Francesca Gino. "Sweeping Dishonesty under the Rug: How Unethical Actions Lead to Forgetting of Moral Rules." Journal of Personality and Social Psychology 102, no. 6 (June 2012): 1164-1177.

\section{Permanent link}

http://nrs.harvard.edu/urn-3:HUL.InstRepos:10996797

\section{Terms of Use}

This article was downloaded from Harvard University's DASH repository, and is made available under the terms and conditions applicable to Open Access Policy Articles, as set forth at http:// nrs.harvard.edu/urn-3:HUL.InstRepos:dash.current.terms-of-use\#OAP

\section{Share Your Story}

The Harvard community has made this article openly available. Please share how this access benefits you. Submit a story.

Accessibility 
Running head: SWEEPING DISHONESTY UNDER THE RUG

Sweeping dishonesty under the rug:

How unethical actions lead to forgetting of moral rules

Lisa L. Shu and Francesca Gino

Harvard University

Forthcoming, Journal of Personality and Social Psychology

The authors thank the Center for Decision Research at the University of North Carolina at Chapel Hill, where the studies were conducted. For helpful feedback on this research, we thank Max Bazerman, Don Moore and Bill Simpson. This research was supported by a grant from the University Research Council at the University of North Carolina at Chapel Hill. Please address correspondence to lshu@fas.harvard.edu or fgino@ hbs.edu. 


\begin{abstract}
Dishonest behavior can have various psychological outcomes. We examine whether one consequence could be the forgetting of moral rules. In four experiments, participants were given the opportunity to behave dishonestly, and thus earn undeserved money, by over-reporting their performance on an ability-based task. Before the task, they were exposed to moral rules (i.e., an honor code). Those who cheated were more likely to forget the moral rules after behaving dishonestly, even though they were equally likely to remember morally irrelevant information (Experiment 1). Furthermore, people showed moral forgetting only after cheating could be enacted but not before cheating (Experiment 2), despite monetary incentives to recall the rules accurately (Experiment 3). Finally, moral forgetting appears to result from decreased access to moral rules after cheating (Experiment 4).
\end{abstract}

Keywords: dishonesty, ethics, moral codes, moral forgetting, unethical behavior 
The public is continually shocked to learn of the deceptive statements of individuals who seemingly lie to juries, peers, and boards. Those guided by a framework for ethical decision making — whether it be an oath, honor code, religious doctrine, or societal norm —often appear to be sincere when they claim to have forgotten these principles, even if they clearly should have recalled them. As an example, consider the case of Eddie Price III, former mayor of Mandeville, Louisiana, who received a sentence to more than five years in federal prison for tax evasion charges in 2010. When he received the sentence, he told the U.S. District Court of New Orleans: “Along the way, I forgot the rules, and I didn't use good judgment."1 Could a publicly elected official who manages tax revenues as part of his job description have forgotten about paying taxes himself? Perhaps he pushed his memory of burdensome moral rules aside, thus dispelling conscience from consciousness.

This paper addresses this possibility by examining whether or not dishonesty impairs memory. ${ }^{2}$ We propose that acting dishonestly motivates people to forget moral rules (e.g., a code of ethics) they had been exposed to prior to having the opportunity to cheat. We also suggest that, once individuals have behaved dishonestly, they unconsciously suppress their memories of the moral norms meant to guide their actions.

\section{The Consequences of Unethical Behavior}

Individuals engage in unethical behavior due to a wide range of factors. Several studies have documented the surprising magnitude by which the situation influences our moral decisions (e.g., Monin \& Jordan, 2009; Zhong, Liljenquist, \& Cain, 2009). In contrast to the fixed traitbased view of morality (e.g., Kohlberg, 1981; Rest, 1986), this recent work has shifted attention to the power of situational factors in determining moral actions and beliefs. Milgram's classic

\footnotetext{
${ }^{1}$ http://www.thesttammanynews.com/articles/2010/06/24/news/doc4c1aa1e370df2782393337.txt

${ }^{2}$ In this paper we use the terms "dishonest," "immoral" and "unethical" synonymously.
} 
studies of obedience revealed the shocking extent to which even a minimal authority figure (a mere experimenter) can influence participants' ethical decisions, such that participants will even inflict significant apparent harm to another human (Milgram, 1974). More recently, research has documented environmental factors influencing individual ethical judgments and decisions - from work incentives and organizational culture (Ferrell, Gresham, \& Fraedrich, 1989; Treviño, 1986) to nuanced cues such as ambient lighting (Zhong, Bohns, \& Gino, 2010), display of wealth in the immediate environment (Gino \& Pierce, 2009), and cleanliness of the environment (Zhong, Strejcek, \& Sivanathan, 2011).

Regardless of the specific source leading to unethical behavior, dishonesty often elicits negative feelings such as guilt (Klass, 1978; Wright, 1971) or discomfort (Noel, 1973; Shaffer, 1975). As proposed by justice theory (Lerner, 1970, 1977), individuals are driven by the need to view themselves as ethical participants in a just world. Because of people's desire to be moral and be seen by others as such, their moral transgressions tend to result in negative feelings and discomfort (Klass, 1978). This discomfort or psychological tension (Festinger, 1957) results from a misalignment between actions (i.e., one's transgressions) and goals or internal beliefs (one's desire to be ethical). In turn, the distress from this tension leads to dissonance motivation (Elliot \& Devine, 1994), or “psychological discomfort that motivates or 'drives' the attitude change process" (Fazio \& Cooper, 1983).

To reduce this psychological distress, people either modify their behavior to bring it closer to their goals, or they modify their beliefs about the behavior (Baumeister \& Heatherton, 1996; Elkin \& Leippe, 1986). For example, after committing moral transgressions, people are more likely to comply with direct requests for help, even when compliance does not ameliorate the harm caused, and even when requesters are unaware of the previous transgression (Carlsmith 
\& Gross, 1969; McMillen, 1970, 1971; McMillen \& Austin, 1971). Another way in which people attenuate the distress of dissonance in the moral domain is through moral disengagement. Moral disengagement allows people to repackage their beliefs regarding ethically questionable behavior so that the behavior is re-construed as ethically permissible (Bandura, 1990; Bandura et al., 1996). Shu, Gino, and Bazerman (2011) found that when facing permissive environments that allow the opportunity to cheat for financial gain, individuals who cheat will subsequently morally disengage to redefine cheating as permissible behavior. This can potentially trigger a slippery slope towards escalating unethicality such that environments allowing for dishonesty lead to ever more lenient ethical standards. This easing of moral standards helps preserve one's moral self-image even while behavior drifts towards ethically questionable terrain.

In this paper, we depart from this research by investigating another potential consequence of unethical behavior: impaired memory of moral rules. We propose that the act of behaving dishonestly after being exposed to moral rules increases individuals' motivation to forget ethically relevant information and suppresses moral rules from memory.

\section{Motivated Forgetting}

People spend time and energy trying to regulate their thoughts and the content of their memories (Payne \& Corrigan, 2007), and they do so in several ways. One way consists of selectively attending to certain aspects of their world (Jacoby, Kelley, \& McElree, 1999). Indeed, how people direct their attention strongly influences what they later recall (Broadbent, 1957). A second way in which people regulate the contents of their memory is by intentionally suppressing unwanted thoughts. The effectiveness of this second type of regulation depends on various factors, such as whether attention or good distracters are available (Wegner, 1994). 
Independent of the way in which people regulate the content of their memory, research has demonstrated that they can forget certain information when they wish (Bjork, 1970; Bjork \& Woodward, 1973). For instance, research has found that people are "revisionist historians" when remembering their pasts (Ross, McFarland, Conway, \& Zanna, 1983), recalling information selectively in ways that support their decisions. In one study, participants decided whether or not to hospitalize a hypothetical patient. Later, when recalling their decision, they remembered more information that supported their decision than information that did not (Dellarosa \& Bourne, 1984). Related research has found that people engage in "choice-supportive memory distortion" for past choices by over-attributing positive features to options chosen and negative features to options not chosen (Mather \& Johnson, 2000; Mather, Shafir, \& Johnson, 2000). This memory bias does not occur for experimenter-assigned selections (Benney \& Henkel, 2006; Mather, Shafir, \& Johnson, 2003), but does occur when people are led to hold an incorrect belief about what their previous choice was (Henkel \& Mather, 2007). Taken together, these findings suggest that motivation is a key component of memory.

In the domain of attitudes and beliefs, people typically claim they have always believed what they currently believe (Bem \& McConnell, 1970; Goethals \& Reckman, 1973). People revise their memories of their prior attitudes in order to preserve consistency with current attitudes (e.g., Bem \& Connell, 1970; Bandura et al., 1996). In studies investigating how selfperception theory accounts for cognitive dissonance, when participants in the standard forcedcompliance experiments are asked to recall their pre-manipulation attitudes, they do not remember they ever held different attitudes (Bem \& McConnell, 1970). Participants in these experiments (all of whom were students) had to write an essay regarding how much control students should have over their course selection decisions. The overwhelmingly popular opinion 
was for students to have more control, but participants randomly assigned to the forcedcompliance condition were told that the experimenter already had enough essays holding the popular opinion, and asked these participants to generate reasons why students should have less control. Writing the counter-attitudinal essays produced the predicted attitude change for these forced-compliance participants. Importantly, participants actually believed their prior attitudes to be the same as their attitudes after the manipulation, and were unaware of any attitude change.

Follow-up studies found similar results in other contexts. For instance, Goethals and Reckman (1973) showed that people tend to distort their recollection of their initial stand on a topic in order to make it consistent with their new attitude. Even when the event to be recalled is harmful conduct toward others, people re-construe it by distorting aspects of the situation so that they can vilify victims (Bandura et al., 1996). This evidence supports the account that people reduce dissonance by revising their memories.

Forgetting information about previous events can certainly be beneficial. Bjork (1989) provides an example of how motivated forgetting can help drivers who park their cars in a new spot every day. Although it is useful to the driver to remember where she parked her car today, it is also equally useful to her to forget where she parked the car the day before since this information would generate confusion about the current location of the car. In the same way, motivated forgetting can help people update their memory in other domains when receiving new information, such as a different time for an important work meeting or a new phone number for the person we are interested in dating. And in the domain of attitudes and beliefs, motivated forgetting can be beneficial for reducing dissonance and regret for options not taken.

At the same time, however, motivated memory errors constitute problems with memory accuracy, which has implications for accountability and learning (Mather, Shafir, \& Johnson, 
2000). This problem is particularly relevant in the ethical domain, since failure to learn from or account for one's past unethical actions may propagate future dishonesty. In four studies, we directly test for evidence of such motivated memory errors in ethical decision making. In particular, we examine whether motivated forgetting of moral rules occurs after one decides to behave unethically. People may selectively forget moral rules that are inconsistent with their actions after behaving dishonestly. We predict that unethical actions lead to the forgetting of moral rules.

\section{Explaining Forgetting of Moral Rules}

We also investigate how forgetting moral rules occurs. Research has found that when people are reminded of something they would prefer not to think about, they try to suppress unwanted memories from awareness (Anderson \& Green, 2001; Anderson \& Levy, 2009; Levy \& Anderson, 2008). Mather and Mangold (2008) examined whether or not people spontaneously suppress negative memories relative to neutral or positive memories. Their studies suggest that individuals recall fewer negatively associated items than either positive or neutral items.

Anderson \& Levy (2009) found that people control their memories for unwanted items by stopping retrieval of these memories. Memory suppression actively recruits the lateral prefrontal cortex to inhibit the retrieval process. Anderson, Bjork, and Bjork (2000) had earlier established that this type of forgetting — as induced by impaired retrieval—is not due to interference from practicing other memories that subsequently crowd out the neglected items. Rather, people exclude unwanted memories from conscious awareness through active suppression, by engaging the lateral prefrontal cortex to reduce hippocampal activity (Anderson \& Levy, 2009). An important marker of this type of forgetting (which occurs at the retrieval stage) is that it necessarily entails motivation; hence it is called "motivated forgetting." 
This work suggests that forgetting unwanted memories (e.g., memories that induce anger, guilt, or shame) may engage an active inhibition process: people automatically control such memories by stopping retrieval through inhibitory control. Through retrieval inhibition, people intentionally reduce activation of memory items (Anderson \& Bjork, 1994). Interestingly, motivated forgetting suggests that people do not completely erase events they want to forget. Rather, access to them is blocked. In the moral domain, prior work has found that dishonesty often leads to feelings of guilt and shame (Wright, 1971), especially when it occurs after exposure to moral rules. Thus, in the same way that people suppress unwanted memories by inhibiting access to these memories, forgetting moral rules after dishonest behavior may result from reduced access to moral concepts in general. We hypothesize that unethical behavior suppresses access to moral concepts, and consequently leads to the forgetting of moral rules.

Overview of the Research

We tested these predictions in four experiments. In our studies, participants have the opportunity to behave dishonestly by over-reporting their performance on an ability-based task in order to earn undeserved money. Before completing the task, they are exposed to moral rules (e.g., an academic honor code). After the task, they complete a memory test with questions about the moral rules they were initially exposed to. We show that, compared to people who behave honestly when given the opportunity to cheat, people who behave dishonestly remember fewer moral rules after cheating. Cheaters and non-cheaters do not differ in general memory ability; after cheating, people are still able to accurately recall neutral items, but not items from a moral code (Experiment 1). Our results also show that impaired memory for moral items is driven by forgetting, not by differences in encoding: people exhibit the forgetting of moral rules only after a concrete act of cheating could be enacted, but not before having the opportunity to cheat 
(Experiment 2). In addition, we demonstrate that forgetting moral rules persists even when people have monetary incentives to recall moral rules accurately (Experiment 3). Finally, we examine the underlying mechanism for forgetting moral rules, and find that it may in fact result from reduced access to moral concepts in general (Experiment 4).

\section{Experiment 1: Forgetting Moral Rules}

Our first experiment tests whether or not dishonest behavior leads to forgetting of moral rules by giving participants the opportunity to cheat after being exposed to a moral code, and then measuring accuracy of recall of moral items. In addition to moral items, we asked participants to read and recall neutral items to rule out an alternative explanation for this hypothesized relationship: cheaters are bad at remembering. That is, there may be an underlying correlation between morality and memory such that those who are unethical are also naturally more forgetful. If cheating is in fact correlated with raw ability to remember, then we would expect participants who cheated to accurately remember fewer neutral (as well as moral) items as compared to participants who did not cheat on a previous task.

It is also possible that individuals who cheat feel nervous or anxious about their actions, and their subsequent performance anxiety renders them more forgetful. If this alternative explanation is valid, then we would expect to find differences in recall on both moral and neutral items. By including a memory task consisting of both neutral and moral items, we test for this possible alternative explanation.

Finally, Experiment 1 includes a control condition where participants could not cheat to test the direction of our hypothesized memory effects: whether cheaters forget, or whether those who resist cheating remember moral information particularly well.

\section{$\underline{\text { Methods }}$}


Participants. One-hundred nine college students at a university in the United States (59\% male; $M_{a g e}=20.74, S D=1.55$ ) participated in the study. They received a $\$ 2$ show-up fee and had the opportunity to earn an extra $\$ 10$ during the study.

Design and procedure. The study employed a 2 (opportunity to cheat: recycling vs. control) X 2 (content of memory task: related to morality vs. neutral) mixed design. We manipulated the first factor between subjects and the second factor within subjects.

The study included two tasks: a comprehension task and a problem-solving task.

Comprehension task. For the comprehension task, we gave participants two different essays to read: a two-page academic honor code (adapted from Shu et al., 2011—see Appendix A) and a similar-length text about eligibility for a Massachusetts license. We chose this neutral material because it was similar to an honor code in that it provided guidelines for how to behave (i.e., it was the rules of the road); however it was different in an important way: it did not pertain to morality per se. Participants were told they would be asked questions about these materials later on in the study. We counterbalanced the order of presentation of the two essays across sessions. The experimenter read the two essays aloud and participants were told to follow them on paper. Then, she explained the instructions for the problem-solving task and provided details for both solving the task and receiving payment.

Problem-solving task. For the problem-solving task, all participants received two sheets of paper. The first was a worksheet with 20 matrices, each containing 12 three-digit numbers (e.g., 7.12; task adapted from Mazar, Amir, \& Ariely, 2008). The second sheet was a collection slip on which participants were supposed to report their performance and answer questions about their gender and age. The collection slip was printed on one side of this sheet, and an example with instructions was printed on the other side of the same sheet of paper. Participants had four 
minutes to find two numbers per matrix that added up to 10; this duration was not sufficient for anyone to solve all 20 matrices. Each matrix had one correct solution. For each matrix solved, participants would receive $\$ 0.50$.

In the recycling condition, participants also received an envelope that contained ten dollars (nine one-dollar bills and four quarters). After the four minutes had passed, participants were asked to count the number of correctly solved matrices, write this number down on the collection slip, walk to a recycling box located in a corner of the room, and deposit their worksheet. Next, they paid themselves the amount earned, and deposited the envelope with the remaining amount and their collection slip in a cardboard box located next to the recycling box. In the control condition, after the four-minute matrix task was over, the experimenter checked how many matrices each participant correctly solved, wrote down their score on the collection slip, and paid them based on their performance.

The matrix task allowed us to directly measure each individual's level of cheating in the recycling condition. In this condition, participants' matrix worksheets were identical with the exception of one digit (in one number of one matrix), which was unique to each individual—a difference imperceptible to participants. The one digit matched the last digit in one of the cells in the matrix given as an example on the other side of the sheet with the collection slip. We later extracted participant worksheets from the recycling box and matched them to their collection slips. As a result, we could compare actual to reported performance in the recycling condition. If these numbers differed for an individual, we could then compute that individual's level of cheating.

Memory task. After engaging in the problem-solving task, participants completed memory tests of the comprehension items they read at the beginning of the study from both the 
honor code and the license manual. We counterbalanced the order of the comprehension questions for these two tests. Each test consisted of seven questions of moderate difficulty about the materials that participants had read. Five were multiple-choice questions and two were openended questions (to be answered with one or two words). Examples of questions on the honor code include: "Who is hurt by an instance of academic dishonesty?" and "Which of the following constitutes academic misconduct, as described in the Honor Code?" Examples of questions on the license manual include: "What will not require the initiation of a license suspension process?" and "Which of these is a situation in which license suspension is mandatory?"

Prior to the study, the questions included in the memory tests were pilot-tested on a nonoverlapping group of participants to confirm there were no differences in the distribution of performance and ease of recall between the two tests. The pilot test also confirmed that the questions were of moderate difficulty. ${ }^{3}$

\section{$\underline{\text { Results }}$}

Amount of cheating. Thirty-two percent of participants (18/56) cheated by over-reporting performance on the matrix task in the recycling condition (see Table 1). Of these participants, twelve over-reported by 2-5 matrices, five over-reported by 7 , and only one participant overreported by 11 matrices. No participant under-reported performance on the matrix task.

Cheating and memory. Our main hypothesis is that the act of cheating leads to the forgetting of moral rules. To test this hypothesis, we first considered participants in the opportunity to cheat condition. A 2 (cheated vs. did not cheat) X 2 (moral vs. neutral items)

\footnotetext{
${ }^{3}$ We were careful to design test materials with possible ceiling and floor effects in mind. Pilot-testing for memory of the honor code and the DMV manual (as well as for the tests in Experiments 3 and 4) helped us design materials to ensure there was no bunching of scores in the upper and lower ranges.
} 
mixed ANOVA revealed a significant interaction effect, $F(1,54)=4.97, p=.03, \eta_{p}{ }^{2}=.08$.

Participants recalled fewer moral items when they cheated than when they did not, $t(54)=-2.67$, $p=.01$, but they remembered about the same number of neutral items, $t(54)<1, p=.64$.

Consistent with these results, the extent of cheating by over-reporting among cheaters correlated significantly with accurate recall of moral items, $r=-0.51, p<.04$, but not with accurate recall of neutral items, $r=0.13, p=.62$.

We also suggested that cheaters would recall fewer moral items than participants who did not cheat, rather than the non-cheaters remembering better. To test this possibility, we conducted further analyses treating the three groups (cheating: recycling/cheated vs. recycling/did not cheat vs. no-opportunity to cheat) as distinct so that we could compare cheaters and non-cheaters to participants in the control condition (i.e., no-opportunity to cheat). We conducted separate analyses using participants' number of correctly recalled moral or neutral items as the dependent measure. ${ }^{4}$ The number of moral items participants recalled varied significantly across conditions, $F(2,106)=5.42, p<.01, \eta_{p}{ }^{2}=.09$ : cheaters in the recycling condition recalled fewer items than both participants in the recycling condition who did not cheat, $p<.01$, and participants who did not have the opportunity to cheat, $p<.01$. We also found no significant differences in the number of moral items participants recalled between the recycling/did-not-cheat condition and the control condition, $p=.79$. These results suggest that cheaters forget moral rules and do not support the alternative account that non-cheaters remember moral items better. Importantly, across the three cheating conditions, participants remembered roughly the same number of neutral items, $F(2,106)<1, p=.57, \eta_{p}{ }^{2}=.01$.

\footnotetext{
${ }^{4}$ We note that there were no differences in the number of question items answered among cheaters, noncheaters, and control participants. This may be partially driven by the nature of the questions we used, most of which were multiple-choice format.
} 


\section{$\underline{\text { Discussion }}$}

These results provide initial support for the hypothesis that unethical actions result in the forgetting of moral rules. Furthermore, these findings indicate that the memory difference observed on the moral items cannot be attributed to a difference in general ability to remember between cheaters and non-cheaters. Cheaters were able to accurately recall neutral items when compared to non-cheaters and control condition participants, but were unable to recall moral items. This lack of a difference for memory of neutral items indicates that cheaters do not have naturally bad memory ability; rather, their forgetfulness extends specifically to items with moral relevance.

Furthermore, the lack of difference in general memory ability (between cheaters, noncheaters, and control participants who did not have the opportunity to cheat) is inconsistent with the account that cheaters showed impaired memory for questions on the honor code because they were nervous and their anxiety interfered with task performance. Cheaters exhibited selective forgetting only for moral items; they recalled neutral items equally well as non-cheaters and control participants did.

\section{Experiment 2: A Case for Forgetting}

Experiment 1 provides evidence that cheaters remember fewer moral items compared to those who do not cheat. An important question remains as to whether cheating affects recall of moral information, or whether people who read moral information less carefully tend to cheat more. In Experiment 2 we test for causality between cheating and forgetting of moral rules by adding an additional memory task for participants to complete before they had the opportunity to cheat.

\section{$\underline{\text { Methods }}$}


Participants. One-hundred twenty-three students at a university in the United States (52\% male; $\left.M_{\text {age }}=21.37, S D=2.16\right)$ agreed to participate in the study. They received a $\$ 2$ show-up fee and had the opportunity to earn an extra $\$ 10$ during the study.

Design. The study employed a 2 (opportunity to cheat: recycling vs. control) X 2 (timing of memory task: before opportunity to cheat vs. after opportunity to cheat) mixed design. We manipulated the first factor between subjects and the second factor within subjects. To assure balance in the number of participants across conditions depending on the choice to cheat in the opportunity-to-cheat condition, we assigned about a third of the participants to the noopportunity-to-cheat control condition and the remaining participants to the opportunity-to-cheat condition.

Procedure. The study used the same procedure as in Experiment 1, with two important differences (see Figure 1 for a depiction of the sequence of tasks used). First, the comprehension task included two different moral codes that the experimenter read aloud for participants at the beginning of the study: the honor code used in Experiment 1, and the Ten Commandments (as in Mazar et al., 2008). The rationale for reading the materials aloud was to ensure that participants were not merely skimming the moral codes. We counterbalanced the order of presentation of the two moral codes across sessions. Second, the study included two memory tasks: one before the problem-solving task and one right after. We counterbalanced the order of presentation of the two memory tasks across sessions.

This design allows us to test whether or not cheaters demonstrate worse performance on the second memory task than the first memory task, when compared to non-cheaters and control group participants. We test for the possibility that people who read moral information less 
carefully tend to cheat more against our hypothesis that cheating affects recall of moral information.

\section{$\underline{\text { Results and Discussion }}$}

Amount of cheating. The results are summarized in Table 2. Thirty-eight percent (30/78) of the participants cheated on the problem-solving task. Of these participants, twenty-five overreported by 2-5 matrices, four over-reported by 6 , and only one participant over-reported by 7 matrices. Just as in Experiment 1, no participant under-reported performance on the matrix task.

Cheating and memory. As before, we first used data only from the opportunity to cheat condition and conducted a 2 (cheated vs. did not cheat) X 2 (timing of memory task) mixed ANOVA. This analysis revealed a significant interaction effect, $F(1,74)=2.93, p=.09, \eta_{p}{ }^{2}=.04$. Participants recalled fewer moral items on the second task when they cheated than when they did not, $t[54]=-2.42, p=.018$, but they remembered about the same number of moral items on the first task, $t[54]<1, p=.80$. Providing further support for the relationship between cheating and forgetting moral rules, cheaters' extent of over-reporting on the matrix task correlated significantly with accurate recall of moral items on the second task, $r=-0.44, p<.02$, but not with accurate recall on the first task, $r=0.07, p=.71$.

Next, we conducted further analyses treating the three groups (recycling/cheated vs. recycling/did not cheat vs. no-opportunity to cheat) as distinct. The number of moral items participants recalled in the second memory task (i.e., the one they completed after the opportunity to cheat) varied across conditions, $F(2,120)=4.82, p=.01, \eta_{p}{ }^{2}=.07$. Cheaters in the recycling condition recalled fewer items than both participants in the recycling condition who did not cheat, $p<.02$, and participants in the control condition with no opportunity to cheat, $p<.01$, with no significant differences between the recycling/did-not-cheat condition and the 
control condition, $p=.64$. However, all participants remembered roughly the same number of moral items across conditions in the first memory task (i.e., the one they completed before the opportunity to cheat), $F(2,120)<1, p=.78, \eta_{p}{ }^{2}=.004$.

These results help us rule out the alternative explanation that people who read moral information less carefully tend to cheat more. Importantly, the findings of Experiment 2 establish that cheating influences recall of moral information through demonstrating that memory differences after the opportunity to cheat were not driven by any pre-existing differences in ability to remember moral rules.

\section{Experiment 3: Cheating and Forgetting Moral Rules}

Although Experiments 1 and 2 provide consistent evidence that cheating leads to the forgetting of moral rules, in both studies, unethical behavior was self-selected. ${ }^{5}$ In Experiment 3 , we address this limitation by randomly assigning participants to either a cheating or no-cheating condition. We use a task where cheating occurs by omission rather than commission for our treatment condition, so that over multiple rounds, cheating is the dominant response.

In addition, in Experiment 3 we manipulate whether or not participants have monetary incentives for accurate recall. We added incentives for the memory task to help detect the possibility that what we call forgetting moral rules is actually a reporting bias among cheaters (i.e., cheaters are withholding the correct answer). We wish to observe whether or not making forgetting costly will impact the extent of moral forgetting. If memory is impaired even when people are paid to remember accurately, this helps further establish the effect of forgetting moral rules after cheating - particularly if cheaters' initial reason for cheating was to earn additional

\footnotetext{
${ }^{5}$ The control conditions in Experiments 1 and 2 partially help address the self-selection of cheaters and non-cheaters in the treatment conditions. The control condition does not allow the opportunity to cheat, but it does include both potential cheaters and potential non-cheaters. Importantly, these groups are in the same proportion as cheaters and non-cheaters in the treatment condition.
} 
money. We also measured the amount of time participants spent completing the memory task to try to detect any differences in effort expended by cheaters and non-cheaters in memory retrieval.

\section{Methods}

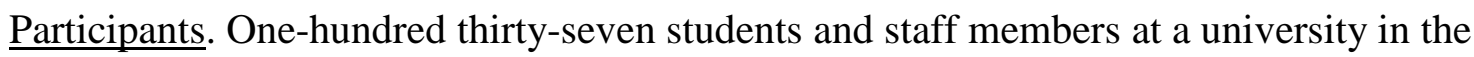
United States (40\% male; $\left.M_{a g e}=26.26, S D=10.86\right)$ agreed to participate in the study.

Design. The study employed a 2 (cheating: cheating vs. no cheating) X 3 (payment for memory task: expected payment vs. unexpected payment vs. no incentives) between-subject design. Participants received a \$2 show-up fee and could earn an additional \$25 throughout the study depending on their performance on the various tasks included.

Procedure. At the beginning of each experimental session, participants were informed they that would be completing a series of tasks. The experiment included three main tasks: a comprehension task, a problem-solving task, and a brief online survey. We included a 2-minute filler task before and after the problem-solving task (see Figure 2 for a depiction of the sequence of tasks used). The comprehension task included a reading task first, and a memory test later on in the study.

Comprehension task. For the comprehension task, participants read the honor code used in Experiments 1 and 2 in a fixed amount of time, and were told they would be asked questions about it later on in the study. The memory task that participants completed before their final online survey included ten multiple-choice and open-ended questions. We manipulated the information participants received regarding the payment for this task. In the no-incentives condition, participants did not receive any additional payment for the memory task. In the expected and unexpected payment conditions, participants received $\$ 1.50$ for every item from 
the honor code they recalled correctly. In the expected-payment conditions, participants were informed about this additional payment after reading the honor code but prior to the problemsolving task. In the unexpected-payment conditions, participants were informed about this additional payment only at the start of the memory task. We included these two payment conditions to detect possible differences in whether or not participants were budgeting (i.e., using mental accounting to allocate) their attention and effort across tasks in different conditions.

Once the allotted time for reading the honor code was over, participants completed a three-minute filler task. They then proceeded to the problem-solving task.

Problem-solving task. Participants engaged in a computer-based mental-arithmetic task in which they had to calculate the answers to 20 different SAT math and logic problems, presented individually (adapted from von Hippel, Lakin, \& Shakarchi, 2005; see also Vohs \& Schooler, 2008). All 20 problems were multiple-choice questions. Participants had 40 seconds to answer each question. The instructions informed participants that they could earn additional money depending on their performance on this task. Specifically, they would receive $\$ 0.50$ for each correct answer up to an additional \$10 in payment. Each problem had only one correct answer. The instructions to the task included two examples of problems so that they could familiarize themselves with the task.

We introduced the cheating manipulation at the beginning of this second task. In the nocheating condition, participants completed the task with no further instructions. In the cheatingcondition, the experimenter informed participants that the computer had a programming glitch: As they were working on each problem, the correct answer would appear on the screen unless they stopped it from being displayed by pressing the space bar within five seconds after the question appeared. The experimenter also informed participants that although no one would be 
able to tell whether they had pressed the space bar or not, they should try to solve the problems on their own. In actuality, this feature of the program was a design choice and not a glitch, and the number of space-bar presses was recorded. Thus, participants have the opportunity to cheat by failing to press the space bar, thus failing to prevent the correct answer from appearing on the screen. In this task, cheating occurs by omission rather than commission, and over multiple rounds rather than in one shot. This procedure makes cheating the dominant response (Jordan et al., 2011; Vohs \& Schooler, 2008; von Hippel, et al., 2005).

Upon completion of the problem-solving task, participants completed another threeminute filler task. This filler task included a 20-item measure of affect, as well as a measure of self-efficacy to explore the potential alternative explanation that differences in memory ability were due to differences in affect or perceived self-efficacy. Next, participants proceeded to the memory task, which they completed on the computer, followed by a short online survey with a few demographic questions.

Measures. Unless otherwise indicated, all items had a 7-point Likert-type response scale anchored at $1=$ Disagree strongly and 7=Agree strongly.

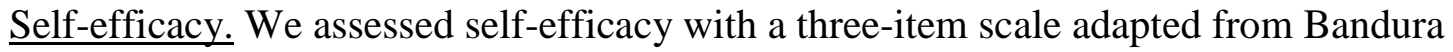
(1990), which asked participants to indicate the extent to which they felt capable, competent, and able to effectively complete the given task, $\alpha=.89$.

Positive and negative affect. Participants completed the 20 -item state version of the Positive and Negative Affect Schedule (Watson, Clark, \& Tellegen, 1988), which has 10 items each for positive affect (e.g., enthusiastic, inspired; $\alpha=.89$ ) and negative affect (e.g., upset, distressed; $\alpha=.93)$. 
Only one of the participants randomly assigned to the cheating condition did not cheat in any of the 20 rounds included in the problem-solving task. We present our analyses by including this participant, but note that the nature and significance of the results do not change when excluding this person from the analyses.

Forgetting moral rules. A 2 (cheating) X 3 (payment for memory task) ANOVA revealed that participants who cheated remembered fewer moral items, $M=4.53, S D=1.89$, than those who did not cheat, $M=6.41, S D=1.61, F(1,131)=45.23, p<.001, \eta_{p}{ }^{2}=.26$. The effect of incentives was significant, $F(2,131)=2.46, p=.09, \eta_{p}{ }^{2}=.04$, and so was the interaction, $F(2,131)=3.74, p=.026$, $\eta_{p}{ }^{2}=.05$ : incentives influenced the number of items participants recalled in the no-cheating condition, $F(2,68)=8.65, p<.001, \eta_{p}{ }^{2}=.20$, but did not influence recall for participants in the cheating condition, $F(2,63)<1$. In the no-cheating condition, participants recalled fewer moral items when they had no incentives for accurate recall, $M=5.52, S D=1.58$, compared to when they expected a payment for accurate recall, $M=6.74, S D=1.32, p<.01$, or learned about this incentive just prior to the memory task, $M=7.19, S D=1.44, p<.001$. The number of items participants correctly recalled did not differ across these two latter conditions, $p=.31$; this suggests that participants did not have an earnings target that might have influenced their effort on the memory task.

Time spent on the memory task. A similar 2 X3 ANOVA using time spent on the memory task as the dependent variable revealed no significant effect for any of our manipulations, all $p s>.42$. We detected no differences in time spent on the memory task across conditions using this implicit measure. We were interested in using reaction time as an unobtrusive measure to help us flag any conditions that appeared to spend more time or effort on the memory task. Although we should be cautious in interpreting a null finding, this lack of a difference does not support the 
account that our cheating manipulation created differences between conditions in subsequent time or effort spent retrieving memories.

Self-efficacy. Our manipulations did not produce significant differences in participants’ feelings of self-efficacy after the problem-solving task, all $p \mathrm{~s}>.53$.

$\underline{\text { Positive and negative affect. Similarly, our manipulations did not produce significant }}$ differences in participants' positive affect, all $p s>.23$. As for negative affect, participants in the cheating condition reported greater negative affect, $M=3.07, S D=1.44$, compared to participants in the no-cheating condition, $M=2.69, S D=1.01, F(1,131)=3.24, p=.074, \eta_{p}{ }^{2}=.024$. However, negative affect did not mediate the relationship between cheating and forgetting because it was not related to the number of moral items participants remembered, $\mathrm{B}=-.16, p=.21$. We note that we replicated the same findings when only considering items specifically related to nervousness (i.e., nervous, distressed, jittery and afraid).

\section{$\underline{\text { Discussion }}$}

The results of Experiment 3 demonstrate that unethical actions lead to forgetting of moral rules. Furthermore, these findings indicate that forgetting moral rules after cheating persists even when participants are incentivized to remember, as participants recalled fewer moral rules after behaving dishonestly even when paid to remember. The forgetting of moral rules was not remedied by financial incentives to remember-even when cheaters were originally pursuing higher earnings through cheating in the first place. Furthermore, reaction time data on the memory task detected no differences in effort exerted by cheaters and non-cheaters.

\section{Experiment 4: Unconscious Suppression of Moral Rules}

So far, our results demonstrate that when people behave dishonestly, they tend to forget the moral rules they were exposed to initially. How does this forgetting of moral rules occur? To 
override memory of moral rules, people may unconsciously inhibit the retrieval of moral rules. Because an individual's awareness cannot be directly observed (Anderson \& Levy, 2009), it is difficult to know whether or not a person prevents previously learned moral rules from entering consciousness. Here, we use a word-completion task to examine whether dishonesty results in an implicit turning away from morality.

Word-completion tests assess implicit cognitive processes (Bassili \& Smith, 1986; Tulving, Schacter, \& Stark, 1982), thus allowing us to test whether or not participants' choice of words and their implicit thought processes are influenced by their behavior on the problemsolving task. In the word-completion test used in Experiment 4, we include words related to ethics that were contained in the honor code, and words unrelated to ethics that were contained in the honor code, in addition to neutral words.

In order to test whether people who cheat after being exposed to moral items unconsciously suppress ethics-related words from their memory, Experiment 4 included two between-subjects manipulations: cheating (as in Experiment 3), and the presence of a comprehension task. This second manipulation determines whether or not participants were initially exposed to moral rules.

If those who cheat after being exposed to moral items are less likely to use words related to ethics and morality in the word-completion tests than those who were not initially exposed to the moral rules (both cheaters and non-cheaters), then we would have evidence for suppression of moral items.

\section{$\underline{\text { Methods }}$}

Participants. One-hundred seventy-seven students and staff members at a university in the Southeastern United States (36\% female; $M_{a g e}=26.73, S D=5.83$ ) participated in the study for pay. 
Design. The study employed a 2 (cheating: cheating vs. no cheating) X 2 (memory task: present vs. absent) between-subjects design. Participants received a $\$ 4$ show-up fee and could earn an additional $\$ 10$ throughout the study depending on their performance on the various tasks included.

Procedure. We used the same procedure as in the no-incentives condition of Experiment 3, but with three main differences (see Figure 3 for a depiction of the sequence of tasks used across conditions). First, half of the participants did not complete the comprehension task. These participants did not read the honor code, nor did they complete a memory task later on.

Second, we included two sets of questions in the memory task. The first set consisted of the same ten questions used in Experiment 3. The second set of questions consisted of questions about the format rather than the content of the honor code (e.g., "How many sections did the honor code include?" and "Were there visible page numbers in the document with the honor code?"). We included this second set of questions to examine whether cheating impairs memory of moral items but frees up resources to better remember other aspects of the honor code unrelated to ethics. We recorded the amount of time participants spent on each set of questions.

Third, we introduced a word-completion task directly after participants completed the problem-solving task. In the word-completion task, participants were given a list of words with letters missing and were asked to fill in the blanks to make complete, meaningful words using the first word that came to mind. We included four sets of words, consisting of four words each: 1) words that could be completed as ethics-related words mentioned in the honor code; 2) words that could be completed as ethics-related words not mentioned in the honor code; 3 ) words that could be completed as neutral words mentioned in the honor code; and 4) words that could be 
completed as neutral words not mentioned in the honor code. We recorded the amount of time participants spent on each of the four sets of words.

\section{$\underline{\text { Results }}$}

All of our participants randomly assigned to the cheating condition cheated in at least one round of the problem-solving task.

We conducted our main analyses including only participants who completed the comprehension task, and examined the effect of our cheating manipulation on the measure included in the study. The goal of the main analyses was twofold: to replicate the results of Experiments 1 through 3 by showing that cheating leads to the forgetting of moral rules, and to examine whether this relationship is mediated by access to ethics-related concepts.

Forgetting moral rules. Participants who cheated remembered fewer moral items related to the content of the honor code, $M=5.41, S D=1.53$, than those who did not cheat, $M=6.07$, $S D=1.54, t(90)=-2.06, p<.05$, but spent the same amount of time on this task, $p=.79$. However, on the questions related to the format of the text included in the honor code, participants in the cheating condition remembered about the same number of items as did participants in the nocheating condition, $M_{\text {cheating }}=7.31, S D=1.36$ vs. $M_{n o-\text { cheating }}=6.95, S D=1.43 ; t(90)=1.24, p=.22$. In addition, both groups spent about the same time on this second set of questions, $p=.87$.

Word-completion task. Our cheating manipulation also influenced the number of words related to ethics that participants recalled, both when the words were from the honor code, $M_{\text {cheating }}=0.23, S D=0.47$ vs. $M_{\text {no-cheating }}=1.07, S D=1.21 ; t(2)=-4.67, p<.001$, and when they were not from the honor code, $M_{\text {cheating }}=1.60, S D=1.12$ vs. $M_{\text {no-cheating }}=2.34, S D=1.02 ; t(92)=-3.31$, $p<.01$. However, cheating did not produce differences in the number of neutral words participants recalled, independent of whether the words were part of the honor code, $t(92)=-1.02$, 
$p=.31$, or not, $t(92)<1, p=.32$. Furthermore, we did not find any significant difference across cheating conditions in the amount of time participants spent on the various components of the word-completion task, all $p s>.24$.

Mediation analysis. We next tested whether the reduced accessibility of ethics-related concepts (both from the honor code and not) mediated the effect of cheating on forgetting moral rules (Baron \& Kenny, 1986). When controlling for cheating, the number of ethics-related words participants used predicted less forgetting, $\beta_{\text {from_honor_code }}=.48, p<.001$ and $\beta_{\text {fgeneral }}=.33, p<.001$. After controlling for the number of ethics-related words (both types), the effect of cheating on forgetting decreased from $\beta=-.21, p<.05$ to $\beta=.10, p=.26$. A bootstrap analysis showed that the 95\% bias-corrected confidence interval for the size of the indirect effects excluded zero, [-1.05, $0.36]$ and $[-0.77,-0.07]$ respectively, suggesting significant indirect effects (MacKinnon, Fairchild, \& Fritz, 2007; Shrout \& Bolger, 2002). These results show that the accessibility of ethics-related concepts mediates the relationship between dishonesty and forgetting moral rules.

$\underline{\text { Ruling out alternative explanations. We next tested whether cheating produced }}$ differences in participants' self-efficacy, $\alpha=.86$, or positive and negative affect, $\alpha=.90$ and $\alpha=.93$, respectively. As in Experiment 3, we found no significant differences in participants' feelings of self-efficacy after the problem-solving regardless of whether or not participants cheated, $t(92)<1$, $p=.48$. As for mood, we found that participants in the no-cheating condition experienced similar positive affect as did participants in the cheating condition, $t(92)=-1.36, p=.18$, but they experienced greater negative affect, $M_{\text {cheating }}=2.72, S D=1.41$ vs. $M_{\text {no-cheating }}=2.12, S D=1.0$, $t(92)=2.30, p=.024$. However, negative affect did not mediate the relationship between cheating and forgetting since it was not related to the number of moral items participants remembered, 
$\mathrm{B}=.06, p=.56$. We note that we replicated the same findings when only considering items specifically measuring nervousness (i.e., nervous, distressed, jittery and afraid).

Suppression of moral items. Next, we conducted analyses considering all participants. We suggested that cheating leads to forgetting moral rules through suppression of moral items. In the analyses presented earlier, we found preliminary support for this hypothesis by showing that accessibility of ethics-related concepts mediated the relationship between cheating and forgetting of moral rules. To provide a stronger test of whether participants suppressed moral items after cheating, we examined the number of ethics-related words that do not appear on the honor code participants used to complete the word-completion task. We used ethics-related words not from the honor code rather than those from the honor code since participants in the nomemory tasks conditions did not read the honor code and thus memory cannot be tested on those items.

We used ethics-related words not from the honor code as the dependent measure in an ANOVA with our four conditions (cheating/moral code vs. no-cheating/moral code vs. cheating/no-moral code vs. no-cheating/no-moral code) as a between-subjects factor. The effect of condition was significant, $F(3,173)=4.55, p<.01, \eta_{p}{ }^{2}=.07$. Post-hoc tests revealed that participants in the cheating/moral code condition reported few items, $M=1.60, S D=1.12$, compared to participants in any of the other three conditions, $p<.03$ in each of the three comparisons. In the other conditions, participants in the cheating/no moral code condition reported 2.09 items on average, $S D=0.98$; those in the no-cheating/no moral code condition reported 2.18 items on average, $S D=1.00$; and those in the no-cheating/moral code condition reported 2.34 items on average, $S D=1.02$. 
As for the neutral words and the other two sets of words included in the word-completion task, we found no significant effect for condition, $p>.51$ in both analyses.

\section{$\underline{\text { Discussion }}$}

The results of Experiment 4 provide further evidence that cheating leads to moral forgetting — but only after exposure to moral rules. Our findings also provide evidence for the mechanism underlying this relationship, and suggest that participants unconsciously suppress items related to morality after being exposed to moral rules initially.

Why did cheaters who were not exposed to moral rules show no suppression of constructs related to morality on the word-completion task? We propose these cheaters had no need to suppress morality in general, as it was not made salient to them that their behavior was inconsistent with any moral code of conduct. Reading the honor code made morality salient (Shu, Gino, \& Bazerman, 2011) and induced objective self-awareness, which brings about selfevaluation against external and internal standards (Duval \& Wicklund, 1972). Participants who read the honor code were primed to include morality in the form of academic honesty among these standards. For these participants, cheating represented a discrepancy between behavior and standards, and they were subsequently motivated to restore consistency (Aronson, Cohen, \& Nail, 1999). Because exposure to the honor code made morality salient (thereby establishing primacy of moral goals) and because cheating on the math problems is inconsistent with these moral goals, cheating led to the suppression of moral concepts for those exposed to the honor code.

\section{General Discussion and Conclusion}

Dishonesty can cause significant damage to interpersonal relationships, organizations, and general society. In extreme cases, deceptive individuals such as Bernie Madoff cause 
spectacular financial ruin to innocent people and institutions. Increasing empirical evidence suggests that such examples are not isolated cases of individual dishonesty. Although people care about being moral and being seen as moral by others, they often cross ethical boundaries repeatedly over time.

How do people maintain their moral self-images, even when they sometimes behave unethically? We know actions and beliefs conspire to support our self-images: we tend to view ourselves as moral individuals even when our behavior strays. We redefine what being ethical means, and use this shifting definition to distort our self-concept such that we are able to ultimately view ourselves positively_or at least avoid viewing ourselves negatively.

The findings in this paper suggest that actions and beliefs have a third co-conspirator: memory. We find that honest and cheating behaviors yield asymmetric consequences in memory. Across four studies, we demonstrated that when participants cheated on an ability-based task, they forgot items from a moral code they had been exposed to at the beginning of the study. Differences in memory ability between cheaters and non-cheaters did not explain this forgetting, as participants accurately recalled neutral items after cheating, but not items from a moral code (Experiment 1). Furthermore, people forgot moral rules only after cheating could be enacted but not before having the opportunity to cheat (Experiment 2), suggesting that there were no differences in the encoding of moral rules. Forgetting moral rules persists even when participants had monetary incentives to recall moral rules accurately (Experiment 3). Finally, we demonstrated that forgetting moral rules is an implicit process resulting from reduced accessibility to moral concepts in memory (Experiment 4).

Are people aware of the consequences of dishonesty on memory? We suspect that they are not. Indeed, when we asked a separate set of students $\left(N=78 ; M_{a g e}=21.72, S D=3.47\right)$ to 
predict the impact of cheating on the forgetting of moral rules, they did not foresee this consequence of unethical behavior. We told these students the average performance on the problem-solving task of participants in a study where half of them had the opportunity to cheat and in fact cheated (recycling condition) and half did not (control condition). We asked students to predict the number of moral items (out of seven, as in Experiments 1 and 2) they thought participants would remember in each of the two experimental conditions. The students correctly predicted that, overall, participants across conditions would remember fewer than seven items: $M_{\text {recycling }}=4.28, S D=1.49$ vs. $M_{\text {control }}=4.19, S D=1.38 ; t(77)=-16.07, p<.001$ and $t(77)=18.00$, $p<.001$ respectively. However, they did not anticipate that recall accuracy would vary across the two described conditions, $F(1,77)<1$. The difference between this prediction and the actual behavior observed in our experiments suggests that dishonesty produces unexpected consequences in memory, and potentially on future moral behavior. That is, people are unaware that unethical behavior leads to the forgetting of moral rules.

\section{Theoretical Implications}

These findings contribute to research on memory and self-perception. Consistent with the evidence that people forget their former attitudes (Bem \& McConnell, 1970) and distort perceptions of their previously held opinions (Goethals \& Reckman, 1973), our experiments demonstrate that people forget external stimuli as well as their internal stands. Furthermore, our findings underscore the work on retrieval-induced forgetting, which shows that forgetting results from suppression at the recall stage, not from neglect caused by practicing other memories (Anderson, Bjork, \& Bjork, 2000).

Our findings also contribute to existing work on moral psychology and ethical decision making. In an attempt to explain unethical behavior, scholars have argued that the best 
explanations for dishonest behavior may reside in underlying psychological processes (Messick \& Bazerman, 1996; Tenbrunsel \& Messick, 2004). Consistent with such arguments, an emerging literature on moral psychology and ethical decision making has identified several psychological factors that consciously or unconsciously influence the decision to behave dishonestly (e.g., Mazar et al., 2008; Chugh, Bazerman, \& Banaji, 2005; Gino, Ayal, \& Ariely, 2009; Gino \& Pierce, 2009; Haidt, 2001; Monin \& Jordan, 2009). This research has focused primarily on the antecedents (cognitive, trait-based, or situational predictors) of immoral actions. We contribute to this research by exploring the psychological consequences of dishonest behavior. Dishonesty can result in increased feelings of guilt or shame, as well as reduced self-esteem (see Klass, 1978 for a thorough review). In turn, these feelings can impact individual behavior. For instance, after a moral transgression, people are often more likely to comply with a request for help (Carlsmith \& Gross, 1969; McMillen, 1970, 1971; McMillen \& Austin, 1971). Here, we have highlighted another important consequence of unethical behavior: forgetting moral rules. After behaving dishonestly, individuals are motivated to forget moral rules that are inconsistent with their previous behavior.

The results of our studies suggest that morality is both malleable and stubborn. It is malleable in that the determinants of our behavior are surprisingly vulnerable to situational influences. But it is also stubborn: our moral self-images persevere in spite of how we behave. Decades of research on cognitive dissonance provide support that attitudes flex to align with behavior, and this flexibility helps us maintain our self-concept. We hold onto our moral selfimages by blurring our definitions of what being moral means. Our research shows that memory also changes to play a role in maintaining our stubborn self-images. After behaving unethically, 
we seemingly close off access to moral concepts and rules meant to guide our behavior. We sweep dishonesty under the rug and leave our unethical trails behind through forgetfulness. $\underline{\text { Limitations and Directions for Future Research }}$

We see several directions for future research that builds on the limitations of our current research. An important direction to pursue is finding the boundary conditions for forgetting. Not all cases of alleged forgetting are equally plausible. To return to our opening example of former mayor Eddie Price, whose defense against tax evasion charges was "I forgot the rules": it is difficult to believe a publicly elected official who manages tax revenues as part of his job description could have simply forgotten to pay taxes himself. We are currently able to detect the forgetting of moral rules for a set of general rules; detecting forgetting of individual specific rules will be an important direction for future research — particularly for cases of serious ethical transgressions that bring individuals to the criminal court.

Another question that arises from this work is whether or not the magnitude of forgetting moral rules differs in instances where dishonesty is an act of commission versus one of omission (e.g., failing to correct an existing unethical situation). Will forgetting be magnified for unethical acts of omission in comparison to unethical acts of commission? Our studies find evidence that forgetting moral rules occurs in situations with both types of dishonest behaviors, but leave open the question of magnitude for future investigation. Exploring this distinction between passive and active unethicality and its impact on memory would be a new area of pursuit at the intersection of memory and morality.

Our experiments provide evidence that after exposure to a moral code, forgetting moral rules results from suppression of rules after cheating. In two experiments, we also measured the

\footnotetext{
${ }^{6}$ http://www.thesttammanynews.com/articles/2010/06/24/news/doc4c1aa1e370df2782393337.txt
} 
emotions participants reported experiencing after cheating. We did not find significant differences on items measuring nervousness, nor did we find evidence supporting the idea that nervousness or fear led to forgetting. Future research could further investigate the role of emotions by considering whether or not forgetting moral rules can alleviate high levels of anxiety and stress caused by cheating. This type of investigation could examine whether or not such feelings might moderate the relationship between cheating and forgetting demonstrated in our studies.

Future work could also examine whether the type of forgetting demonstrated in our studies results from actions that are negative and potentially harmful to others but not unethical. For instance, making a student cry by failing her on an exam when the exam in fact deserved a failing score may produce a sense of discomfort or dissonance in the teacher, especially when she had high expectations for the student. We believe that in cases like this one where morality is not part of the picture, we would not observe forgetting moral rules. Further studies that manipulate both the valence of the action and its ethicality independently can deepen our understanding of the forgetting of moral rules.

Finally, future research could investigate forgetting in other moral domains to extend our findings beyond dishonesty through cheating. Would we forget moral rules after lying to an authority figure or forging excuses in order to shirk responsibilities? Establishing when memory conspires with morality would help determine the boundaries within which our current findings apply to other types of unethical behaviors.

\section{Conclusion}

While recognizing the important differences between laboratory studies and real-world settings, we believe our results have important implications for ethical decision making. Our 
internal and external moral codes (including mission statements and honor codes) can effectively guide our behavior, especially when morality is made salient at times when dishonesty is tempting. But when we cross ethical boundaries, we are more likely to forget moral rules. Such a continuous feedback loop could propagate even more deviant behavior. When memory conspires with morality, we forget the ethical boundaries that we trespass, and cloak our dishonesty under the veil of forgetfulness. 


\section{Appendix A}

Academic honor code used in Experiments 1-4

\section{Section 1. Statement of Purpose}

The members of the University Community believe that the fundamental objective of the Institution is to provide the students with a high quality education while developing in them a sense of ethics and social responsibility.

We believe that any instance of dishonesty hurts the entire community. It is with this in mind that we have set forth a Student Honor Code at the University.

\section{Section 2. Objectives}

- An Honor Code at the University aims to cultivate a community based on trust, academic integrity and honor. It specifically aims to accomplish the following:

- Ensure that students, faculty and administrators understand that the responsibility for upholding academic honesty at the University lies with them;

- Prevent any students from gaining an unfair advantage over other students through academic misconduct;

- Ensure that students understand that academic dishonesty is a violation of the profound trust of the entire academic community.

\section{Section 3. Student Responsibilities}

The immediate objective of an Honor Code is to prevent any students from gaining an unfair advantage over other students through academic misconduct

- Academic misconduct is any act that does or could improperly distort student grades or other student academic records. Such acts include but need not be limited to the following:

- Possessing, using or exchanging improperly acquired written or verbal information in the preparation of any essay, laboratory report, examination, or other assignment included in an academic course;

- Substitution for, or unauthorized collaboration with, a student in the commission of academic requirements;

- Submission of material that is wholly or substantially identical to that created or published by another person or persons, without adequate credit notations indicating authorship (plagiarism);

- False claims of performance or work that has been submitted by the claimant.

While these acts constitute assured instances of academic misconduct, other acts of academic misconduct may be defined by the professor.

Students must sign the Honor Agreement affirming their commitment to uphold the Honor Code before becoming a part of the University community. The Honor Agreement may reappear on 
exams and other assignments to remind students of their responsibilities under the Academic Honor Code.

\section{Section 4. Faculty Responsibilities}

Faculty members are expected to create an environment where honesty flourishes. In creating this environment, faculty members are expected to do the following:

- Make known to their class as specifically as possible what constitutes appropriate academic conduct as well as what comprises academic misconduct. This includes but is not limited to the use of previously submitted work, collaborative work on homework, etc.

- Provide copies of old exams to the University library for students to review;

- Avoid the re-use of exams;

- Include a paragraph containing information about the University Academic Honor Code on the syllabus for each class they teach.

In addition to the expectations listed above, faculty have the authority to superimpose their own interpretations on some aspects of academic conduct including, but not limited to, the following:

- Old exams for use during open-book exams;

- Collaboration on out of class assignments;

- Use of previously submitted out of class assignments. 


\section{References}

Anderson, M. C., \& Bjork, R. A. (1994). Mechanisms of inhibition in long-term memory: A new taxonomy. In T. H. Carr \& D. Dagenbach (Eds.), Inhibitory processes in attention, memory, and language (pp. 265-325). San Diego, CA: Academic Press.

Anderson, M. C., Bjork, E. L., \& Bjork, R. A. (2000). Retrieval-induced forgetting: Evidence for a recall-specific mechanism. Psychonomic Bulletin \& Review, 7(3), 522-530.

Anderson, M. C., \& Green, C. (2001). Suppressing unwanted memories by executive control. Nature, 410, 366-369.

Anderson, M. C., \& Levy, B. J. (2009). Suppressing unwanted memories. Current directions is Psychological Science, 18(4), 189-194.

Aronson, J., Cohen, G. L., \& Nail, P. R. (1999). Self-affirmation theory: An update and appraisal. In E. Harmon-Jones \& J. Mills (Eds.), Cognitive dissonance: Progress on a pivotal theory in social psychology (pp. 127-148). Washington, DC: American Psychological Association.

Bandura, A. (1990). Selective activation and disengagement of moral control. Journal of Social Issues, 46, 27-46.

Bandura, A., Barbaranelli, C., Caprara, G., \& Pastorelli, C. (1996). Mechanisms of moral disengagement in the exercise of moral agency. Journal of Personality and Social Psychology, 71(2), 364-374.

Baron, R. M., \& Kenny, D. A. (1986). The moderator-mediator variable distinction in social psychological research: Conceptual, strategic, and statistical considerations. Journal of Personality and Social Psychology, 51(6), 1173-1182. 
Bassili, J. N., \& Smith, M. C. (1986). On the spontaneity of trait attribution: Converging evidence for the role of cognitive strategy. Journal of Personality and Social Psychology, $50,239-245$.

Baumeister, R. F., \& Heatherton, T. F. (1996). Self-regulation failure: An overview. Psychological Inquiry, 7, 1-15.

Bem, D. J., \& McConnell, H. K. (1970). Testing the self-perception explanation of dissonance phenomena: on the salience of premanipulation attitudes. Journal of Personality and Social Psychology, 14(1), 23-31.Benney, K. S., \& Henkel, L. A. (2006). The role of free choice in memory for past decisions. Memory, 14(8), 1001-1011.

Benney, K. E., \& Henkel, L. A. (2006). The role of free choice in memory biases for past decisions. Memory, 14, 1001-1011.

Bjork, R. A. (1970). Positive forgetting: The noninterference of items intentionally forgotten. Journal of Verbal Learning and Verbal Behavior, 9, 255-268.

Bjork, R. A. (1989). Retrieval inhibition as an adaptive mechanism in human memory. In Fergus I. M. Craik \& Henry L. Roediger III (Eds.), Varieties of memory and consciousness: Essays in honour of Endel Tulving (pp. 309-330). Hillsdale, NJ: Lawrence Erlbaum Associates, Inc. $445 \mathrm{pp}$.

Bjork, R. A., \& Woodward, A. E. (1973). Directed forgetting of individual words in free recall. Journal of Experimental Psychology, 99, 22-27.

Broadbent, D. E. (1957). A mechanical model for human attention and immediate memory. Psychological Review, 64, 205-215.

Carlsmith, J. M., \& Gross, A. E. (1969). Some effects of guilt on compliance. Journal of Personality and Social Psychology, 11, 232-239. 
Chugh, D., Bazerman, M. H., \& Banaji, M. R. (2005). Bounded ethicality as a psychological barrier to recognizing conflicts of interest. In D. A. Moore, D. M. Cain, G. F. Loewenstein, \& M. H. Bazerman (Eds.), Conflicts of interest: Problems and solutions from law, medicine and organizational settings. London: Cambridge University Press.

Dellarosa, D., \& Bourne, L. E. (1984). Decisions and memory: Differential retrievability of consistent and contradictory evidence. Journal of Verbal Learning and Verbal Behavior, 23, 669-682.

Duval, T. S., \& Wicklund, R. A. (1972), A Theory of Objective Self Awareness. New York: Academic Press.

Elkin, R.A., \& Leippe, M.R. (1986). Physiological arousal, dissonance, and attitude change: Evidence for a dissonance arousal link and a “don’t remind me” effect. Journal of Personality and Social Psychology, 51, 55-65.

Elliot, A.J., \& Devine, P.G. (1994). On the motivational nature of cognitive dissonance: Dissonance as psychological discomfort. Journal of Personality and Social Psychology, 67, 382-394.

Fazio, R. H., \& Cooper, J. (1983). Arousal in the dissonance process. In J. T. Cacioppo R. E. Petty (Eds.), Social psychophysiology (pp. 122-152). New York: Guilford Press.

Ferrell, O. C., Gresham, L. G., \& Fraedrich, J. (1989). A synthesis of ethical decision models for marketing. Journal of Macromarketing, 9, 55-64.

Festinger, L. A. (1957). A theory of cognitive dissonance. Stanford, CA: Stanford University Press.

Gino, F., Ayal, S., \& Ariely, D. (2009). Contagion and differentiation in unethical behavior: The effect of one bad apple on the barrel. Psychological Science, 20, 393-398. 
Gino, F., \& Pierce, L. (2009). The abundance effect: Unethical behavior in the presence of wealth. Organizational Behavior and Human Decision Processes, 109(2), 142-155.

Goethals, G. R., \& Reckman, R. F. (1973). The perception of consistency in attitudes. Journal of Experimental Social Psychology, 9(6), 491-501.

Haidt, J. (2001). The emotional dog and its rational tail: A social intuitionist approach to moral judgment. Psychological Review, 108, 814-834.

Henkel, L. A. \& Mather, M. (2007). Memory attributions for choices: How beliefs shape our memories. Journal of Memory and Language, 57, 163-176.

Jacoby, L. L., Kelley, C. M., \& McElree, B. D. (1999). The role of cognitive control: Early selection versus late correction. In S. Chaiken \& Y. Trope (Eds.), Dual process theories in social psychology (pp. 383-402). New York, NY: Guilford Press.

Jordan, J., Mullen, E., \& Murnighan, J. K. (2011). Striving for the moral self: The effects of recalling past moral actions on future moral behavior. Personality and Social Psychology Bulletin, 37(5), 701-713.

Klass, E. T. (1978). Psychological effects of immoral actions: The experimental evidence. Psychological Bulletin 85(4), 756-771.

Kohlberg, L. (1981). Essays on Moral Development, Vol. I: The Philosophy of Moral Development. Harper \& Row.

Lerner, M. J. (1970). The desire for justice and reactions to victims. In J. Macaulay \& L. Berkowitz (Eds.), Altruism and helping behavior. New York: Academic Press.

Lerner, M. J. (1977). The justice motive: Some hypotheses as to its origins and forms. Journal of Personality, 45, 1-52. 
Levy, B. J., \& Anderson, M. C. (2008). Individual differences in suppressing unwanted memories: The executive deficit hypothesis. Acta Psychologica, 127, 623-635.

MacKinnon, D. P., Fairchild, A. J., \& Fritz, M. S. (2007). Mediation analysis. Annual Review of Psychology, 58, 593-614.

Mather, M., \& Johnson, M. K. (2000). Choice-supportive source monitoring: Do our decisions seem better to us as we age? Psychology and Aging, 15, 596-606.

Mather, M., \& Mangold, S. (2008). When repeated reminders lead to forgetting: Spontaneous suppression of negative associations. International Journal of Psychology, 43, 643.

Mather, M., Shafir, E., \& Johnson, M. K. (2000). Misremembrance of options past: Source monitoring and choice. Psychological Science, 11, 132-138.

Mather, M., Shafir, E., \& Johnson, M. K. (2003). Remembering chosen and assigned options. Memory \& Cognition, 31, 422-433.

Mazar, N., Amir, O., \& Ariely, D. (2008). The dishonesty of honest people: A theory of selfconcept maintenance. Journal of Marketing Research, 45, 633-644.

McMillen, D. L. (1970). Transgression, fate control, and compliant behavior. Psychonomic Science, 21, 103-104.

McMillen, D. L. (1971). Transgression, self-image, and compliant behavior. Journal of Personality and Social Psychology, 20, 176-179.

McMillen, D. L., \& Austin, J. B. (1971). Effects of positive feedback on compliance following transgression. Psychonomic Science, 24, 59-61.

Messick, D. M., \& Bazerman, M. H. (1996). Ethical leadership and the psychology of decision making. Sloan Management Review, 9-22.

Milgram, S. (1974). Obedience to authority: An experimental view. New York: Harper and Row. 
Monin, B., \& Jordan, A.H. (2009). Dynamic moral identity: A social psychological perspective. In D. Narvaez \& D. Lapsley (Eds), Moral self, identity and character: Prospects for a new field of study, Cambridge University Press.

Noel, R. C. (1973). Transgression-compliance: A failure to confirm. Journal of Personality and Social Psychology, 27, 151-153.

Payne, B. K., \& Corrigan, E. (2007). Emotional constraints on intentional forgetting. Journal of Experimental Social Psychology, 43, 780-786.

Rest, J. R. (1986). Moral development: Advances in research and theory. New York: Praeger.

Ross, M., McFarland, C., Conway, M., \& Zanna, M. P. (1983). The reciprocal relation between attitudes and behaviour recall: Committing people to newly formed attitudes. Journal of Personality and Social Psychology, 45, 257-267.

Shaffer, D. R. (1975). Some effects of consonant and dissonant attitudinal advocacy on initial attitude salience and attitude change. Journal of Personality and Social Psychology, 32, $160-168$.

Shrout, P. E., \& Bolger, N. (2002). Mediation in experimental and non-experimental studies: New procedures and recommendations. Psychological Methods, 7, 422-445.

Shu, L. L., Gino, F., \& Bazerman, M. H. (2011). Dishonest deed, clear conscience: When cheating leads to moral disengagement and motivated forgetting. Personality and Social Psychology Bulletin, 37(3), 330-349.

Tenbrunsel, A. E., \& Messick, D. M. (2004). Ethical fading: The role of self-deception in unethical behavior. Social Justice Research, 17, 223-236.

Treviño, L. K. (1986). Ethical decision-making in organizations: a person-situation interactionist model. Academy of Management Review, 11, 601-617. 
Tulving, E., Schacter, D. L., \& Stark, H. A. (1982). Priming effects in word-fragment completion are independent of recognition memory. Journal of Experimental Psychology: Learning, Memory and Cognition, 8, 336-342.

Vohs, K. D., \& Schooler, J. W. (2008). The value of believing in free will: Encouraging a belief in determinism increases cheating. Psychological Science, 19, 49-54.

von Hippel W., Lakin J.L., \& Shakarchi R.J. (2005). Individual differences in motivated social cognition: The case of self-serving information processing. Personality and Social Psychology Bulletin, 31, 1347-1357.

Watson, D., Clark, L. A., \& Tellegen, A. (1988). Development and validation of brief measures of Positive and Negative Affect: The PANAS Scales. Journal of Personality and Social Psychology, 54,1063-1070.

Wegner, D. M. (1994). Ironic processes of mental control. Psychological Review, 101, 34-52.

Wright, D. (1971). The psychology of moral behavior. Baltimore, Md.: Penguin Books.

Zhong, C., Bohns, V. K., \& Gino, F. (2010). Good lamps are the best police: Darkness increases dishonesty and self-interested behavior. Psychological Science, 21, 311-314.

Zhong, C. B., Liljenquist, K., \& Cain, D. M., (2009). Moral self-regulation: Licensing \& compensation, In De Cremer, D. (Ed.) Psychological perspectives on ethical behavior and decision making. Greenwich, CT: Information Age Publishing.

Zhong, C. B., Strejcek, B., \& Sivanathan, N. (2010). A clean self can render harsh moral judgment. Journal of Experimental Social Psychology, 46(5), 859-862. 
Figure Captions

Figure 1. Design and procedure of Experiment 2

Figure 2. Design and procedure of Experiment 3

Figure 3. Design and procedure of Experiment 4

Figure 1

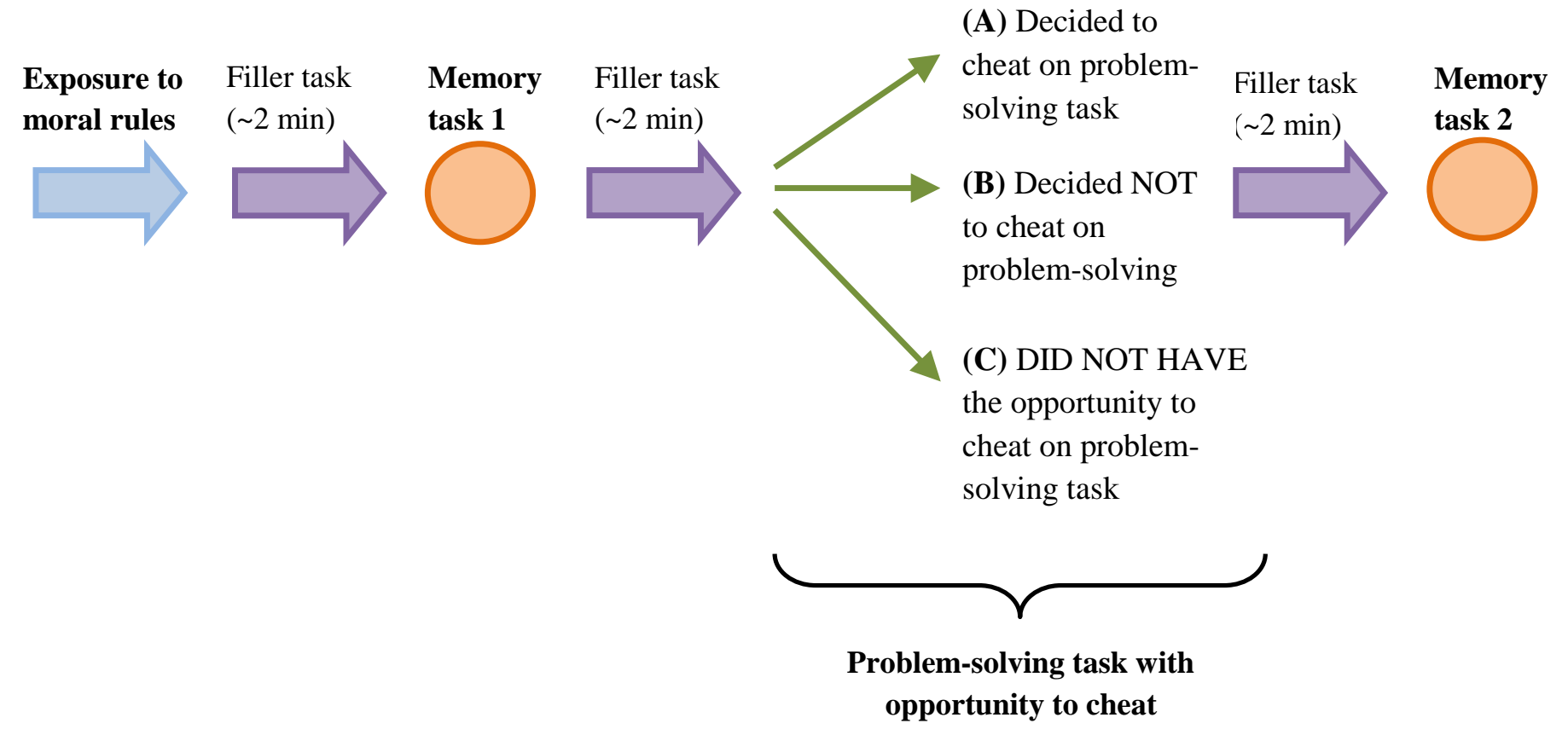

Figure 2

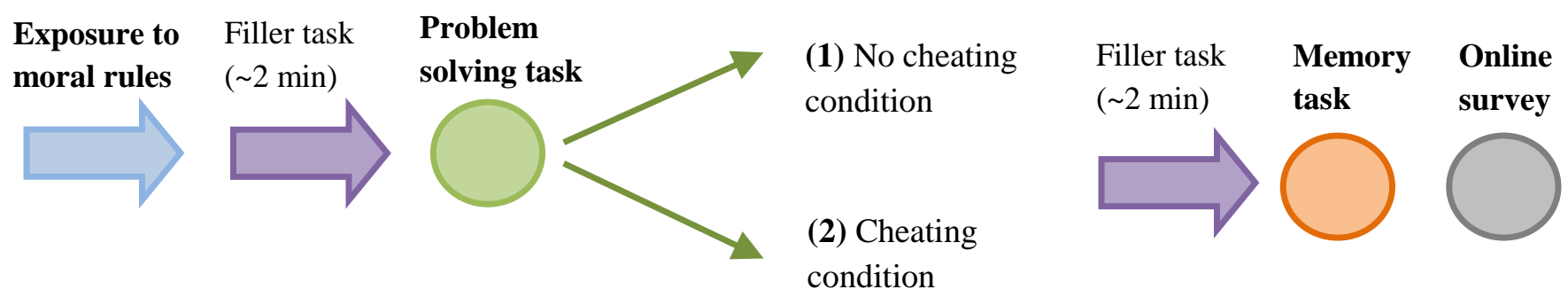


Figure 3

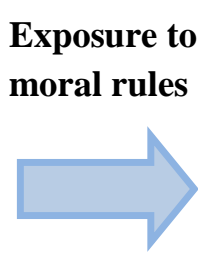

Filler task

$$
\text { ( 2 min) }
$$

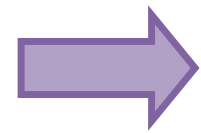

No exposure Filler task

to moral $\quad(\sim 2 \mathrm{~min})$

rules
Problem

solving task

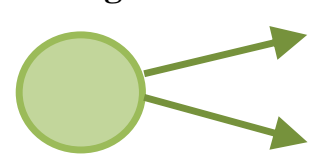

(1) No cheating

condition

(2) Cheating

condition

(1) No cheating condition

(2) Cheating condition

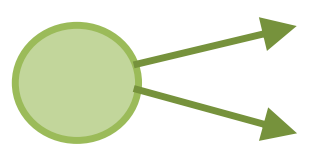

MEMORY TASK CONDITION
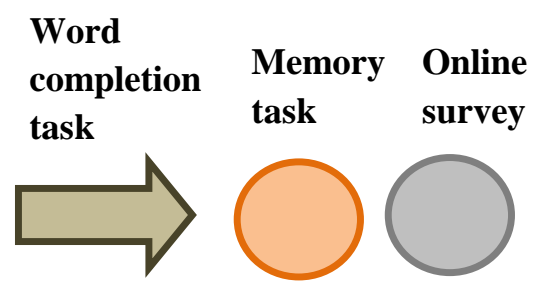

Word completion

task NO MEMORY TASK CONDITION
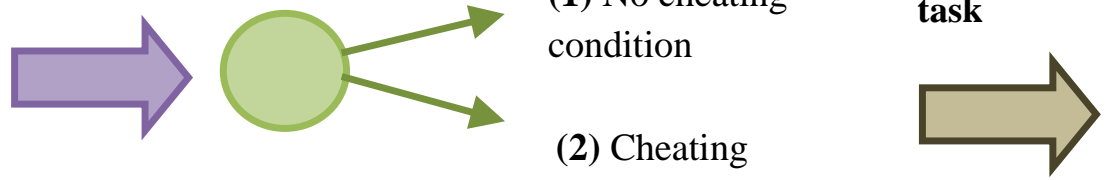
Tables

Table 1

Summary of results, Experiment 1. Standard deviations are reported in parentheses

\begin{tabular}{lccc}
\hline & \multicolumn{2}{c}{ Had opportunity to cheat } & $\begin{array}{c}\text { Did not have } \\
\text { opportunity to cheat }\end{array}$ \\
\hline $\mathrm{N}$ & Did not cheat & Cheated & Control \\
\cline { 2 - 4 } Actual performance on & 38 & 18 & 53 \\
matrix task & 7.68 & 7.44 & 7.51 \\
Self-reported performance & 7.68 & $(S D=2.15)$ & $(S D=3.31)$ \\
& $(S D=3.28)$ & $(S D=3.16)$ & 7.51 \\
Performance inflation & & 4.89 & $(S D=3.31)$ \\
Accurately recalled moral & 3.71 & $(S D=2.35)$ & \\
items on memory task & $(S D=1.78)$ & $(S D=1.85)$ & $(S D=1.27)$ \\
Accurately recalled neutral & 3.79 & 4.00 & 4.13 \\
items on memory task & $(S D=1.51)$ & $(S D=1.61)$ & $(S D=1.48)$ \\
\hline
\end{tabular}


Table 2

Summary of results, Experiment 2. Standard deviations are reported in parentheses

\begin{tabular}{lccc}
\hline & \multicolumn{2}{c}{ Had opportunity to cheat } & $\begin{array}{c}\text { Did not have } \\
\text { opportunity to cheat }\end{array}$ \\
\hline $\mathrm{N}$ & Did not cheat & Cheated & Control \\
\cline { 2 - 4 } Actual performance on & 48 & 30 & 45 \\
matrix task & 7.67 & 7.33 & 7.56 \\
Self-reported performance & $(S D=2.53)$ & $(S D=2.40)$ & $(S D=2.54)$ \\
& 7.67 & 11.30 & 7.56 \\
Performance inflation & $(S D=2.53)$ & $(S D=3.05)$ & $(S D=2.54)$ \\
& & 3.97 & \\
$\begin{array}{l}\text { Accurately recalled moral } \\
\text { items on memory task 1 }\end{array}$ & $(S D=1.58)$ & $(S D=1.92)$ & $(S D=1.59)$ \\
(before opportunity to & & & \\
cheat) & & & \\
$\begin{array}{l}\text { Accurately recalled moral } \\
\text { items on memory task 2 } \\
\text { (after opportunity to cheat })\end{array}$ & $(S D=1.99)$ & $(S D=1.60)$ & $(S D=1.54)$ \\
\hline
\end{tabular}

